AP01

The Relation between Regional (Palaeo-)stress Engines, Sand Machines, and Carbonate Factories in the Middle East Region

A. Koopman* (Shell International E\&P BV)

For abstract, PTO

No full paper available 


\title{
15379 The relation between regional (palaeo-) stress engines, sand machines, and carbonate factories in the Middle East region
}

\author{
Anton Koopman (Shell <anton.koopman@shell.com>)
}

Relative sea-level fluctuations exert primary control on patterns of sediment dispersal and differential erosion. Generally subtle, but locally significant lateral variations of "carbonate factories" and "sand machines", are critically controlled by the combined effects of the global eustacy record and regionalscale structural evolution of the Arabian Plate. It is generally accepted that regional-scale structural development is related to plate-boundary forces, associated with plate-tectonic models of Neo-Tethys, throughout its Mesozoic history. An assessment of the main driving forces ("stress engines") involved may contribute to better-constrain structural framework models for the Mesozoic Middle East region, including the Late Jurassic-Early Cretaceous time period. 